Cite as: H. Rincon-Arevalo et al., Sci. Immunol. 10.1126/sciimmunol.abj1031 (2021).

\title{
CORONAVIRUS
}

\section{Impaired humoral immunity to SARS-CoV-2 BNT162b2 vaccine in kidney transplant recipients and dialysis patients}

\author{
Hector Rincon-Arevalo ${ }^{1,2,3,4+}$, Mira Choi ${ }^{1+}$, Ana-Luisa Stefanski ${ }^{2,3+}$, Fabian Halleck ${ }^{1}$, Ulrike Weber ${ }^{1}$, Franziska \\ Szelinski ${ }^{2,3}$, Bernd Jahrsdörfer ${ }^{5}$, Hubert Schrezenmeier ${ }^{5}$, Carolin Ludwig ${ }^{5}$, Arne Sattler ${ }^{6}$, Katja Kotsch $^{6}$, \\ Alexander Potekhin ${ }^{7}$, Yidan Chen ${ }^{2,3}$, Gerd R. Burmester ${ }^{2}$, Kai-Uwe Eckardt', Gabriela Maria Guerra ${ }^{3}$, Pawel \\ Durek $^{3}$, Frederik Heinrich ${ }^{3}$, Marta Ferreira-Gomes ${ }^{3}$, Andreas Radbruch ${ }^{3}$, Klemens Budde', Andreia C. Lino ${ }^{3}$, \\ Mir-Farzin Mashreghi ${ }^{3,8,9}$, Eva Schrezenmeier ${ }^{1,3,10^{+*}}$, Thomas Dörner ${ }^{2,3+}$

\begin{abstract}
'Department of Nephrology and Intensive Medical Care, Charité Universitätsmedizin Berlin, corporate member of Freie Universität Berlin and Humboldt-Universität zu Berlin, Berlin, Germany. ${ }^{2}$ Department of Rheumatology and Clinical Immunology, Charité Universitätsmedizin Berlin, corporate member of Freie Universität Berlin and Humboldt-Universität zu Berlin, Berlin, Germany. ${ }^{3}$ Deutsches Rheumaforschungszentrum (DRFZ), Berlin, Germany. ${ }^{4}$ Grupo de Inmunología Celular e Inmunogenética, Facultad de Medicina, Instituto de Investigaciones Médicas, Universidad de Antioquia UdeA, Medellín, Colombia. ${ }^{5}$ Institute of Transfusion Medicine, Ulm University, Ulm, Germany and Institute for Clinical Transfusion Medicine and Immunogenetics. German Red Cross Blood Transfusion Service Baden-Württemberg - Hessen and University Hospital UIm, Ulm, Germany. ${ }^{6}$ Department for General and Visceral Surgery, Charité Universitätsmedizin Berlin, corporate member of Freie Universität Berlin and Humboldt-Universität zu Berlin, Berlin, Germany. ${ }^{7}$ MVZ Diaverum Neubrandenburg, Neubrandenburg, Germany. ${ }^{8}$ BIH Center for Regenerative Therapies (BCRT), Charité Universitätsmedizin Berlin, Berlin, Germany. ${ }^{9}$ Department of Pediatric Pulmonology, Immunology and Critical Care Medicine, Charité-Universitätsmedizin Berlin, corporate
\end{abstract} \\ member of Freie Universität Berlin, Humboldt-Universität zu Berlin, and Berlin Institute of Health, Berlin, Germany. ${ }^{10}$ Berlin Institute of Health (BIH), Berlin, Germany. \\ ${ }^{\dagger}$ These authors contributed equally to this work. \\ *Corresponding author. Email: eva-vanessa.schrezenmeier@charite.de
}

Patients with kidney failure are at increased risk for SARS-CoV-2 infection making effective vaccinations a critical need. It is not known how well mRNA vaccines induce $B$ and plasma cell responses in dialysis patients (DP) or kidney transplant recipients (KTR) compared to healthy controls (HC). We studied humoral and B cell responses of $35 \mathrm{HC}, 44$ DP and $40 \mathrm{KTR}$. Markedly impaired anti-BNT162b2 responses were identified among KTR and DP compared to HC. In DP, the response was delayed (3-4 weeks after boost) and reduced with anti-S1 IgG and IgA positivity in $70.5 \%$ and $68.2 \%$, respectively. In contrast, KTR did not develop IgG responses except one patient who had a prior unrecognized infection and developed anti-S1 IgG. The majority of antigen-specific $B$ cells $(R B D+)$ were identified in the plasmablast or post-switch memory $B$ cell compartments in $\mathrm{HC}$, whereas RBD+ $B$ cells were enriched among pre-switch and naïve $B$ cells from DP and KTR. The frequency and absolute number of antigen-specific circulating plasmablasts in the cohort correlated with the Ig response, a characteristic not reported for other vaccinations. In conclusion, these data indicated that immunosuppression resulted in impaired protective immunity after mRNA vaccination, including Ig induction with corresponding generation of plasmablasts and memory $B$ cells. Thus, there is an urgent need to improve vaccination protocols in patients after kidney transplantation or on chronic dialysis.

\section{INTRODUCTION}

COVID-19 leads to a high morbidity and mortality especially among patients with kidney failure (1). Dialysis patients (DP) and kidney transplant recipients (KTR) are at increased risk of developing COVID-19 and experiencing a severe infection, due to exposure risk in the health care system, their comorbidities, and their impaired immune function from kidney failure or immunosuppressive medications. For this vulnerable population, vaccination is of the utmost importance.
The mRNA
SARS-CoV-2 vaccine
BNT162b2

(BioNTech/Pfizer) has demonstrated efficacy in healthy individuals in a clinical study (2) and under real-world conditions (3). Recent data described a lower serological response to an mRNA vaccine in dialysis patients (4) and kidney transplant recipients (5), suggesting an overall diminished vaccine response. Whereas numerous studies have addressed the consequences of conventional vaccines on $B$ and plasma cells (68 ) and corresponding Ig levels, nothing is known yet about the $\mathrm{B}$ lineage consequences in response to an mRNA vaccine among healthy controls and immunocompromised patients. 
The ongoing uremic state in kidney failure patients leads to an immune dysfunction on various levels of innate and adaptive immunity. Restoring kidney function by kidney transplantation does not fully restore cellular and adaptive immunity while immunosuppressive drugs impair protective immunity further. Thus, kidney failure patients (with or without kidney transplant) show an increased susceptibility for infection and viral-associated cancers (9-11).

Previous studies in kidney failure patients (with or without kidney transplant) report markedly diminished response to vaccinations. This has led to an adaption of vaccination protocols with either higher initial vaccine doses or more frequent booster doses $(12,13)$. If such adaptations of the protocol are required for the COVID-19 mRNA vaccines or if alternate adjuvanted vaccines are necessary is not yet known.

The induction of B cell memory by mRNA vaccines and the relation to humoral immune response is largely underinvestigated, especially studies of immunocompromised cohorts. Upon natural acute SARS-CoV-2 infection, immunological memory (antibodies and memory B cells) is shown to last for at least 8 months (14-16). In patients with chronic kidney disease, such data are largely lacking, although prolonged time of viral shedding with impaired virus clearance is reported and likely related to impaired cell-mediated immunity (17).

In this study, we compared the characteristics of the humoral and antigen-specific B cell immune response against the mRNA vaccine BNT162b2 between healthy controls and patients with kidney failure treated by maintenance hemodialysis or kidney transplantation. We found a diminished humoral response to BNT162b2, and a lack of proper B lineage memory formation including RBD-specific plasmablasts and post-switch memory B cells.

\section{RESULTS}

\section{Cohorts and patient characteristics}

For this study, we recruited 35 healthy controls (HC), 41 patients on maintenance hemodialysis, 4 peritoneal dialysis patients and 40 KTR. Hemodialysis and peritoneal dialysis (PD) patients did not significantly differ in age and vaccine response and were therefore grouped together. After written informed consent, serum and peripheral blood mononuclear cells (PBMCs) were collected before vaccination (baseline) and $7 \pm 2$ days after boost vaccination (second dose), respectively. Serological follow-up was available in DP and KTR patients 3-4 weeks after boost. Due to local vaccination guidelines, $\mathrm{HC}$, who were mainly health care workers, were significantly younger than DP $(p<0.01)$. DP were significantly older than KTR. As known for patients with kidney failure (18), a majority of DP and KTR were male. The median time on dialysis was 5.5 years (IQR, 2.0, 9.0). Among KTR only one patient was transplanted less than one year ago and median time after transplantation was 5.0 years (IQR. 2.0, 10.0). KTR were on a uniform immunosuppressive regimen with mycophenolate mofetil (MMF) in 39/40, steroid in 37/40 and calcineurin inhibitor (CNI) in 37/40 patients. Demographics are summarized in Table 1. To identify previously SARS-CoV-2 infected individuals we measured anti-nucleocapsid protein (NCP) antibodies $7 \pm 2$ days after boost, which is not a component of BNT162b2. Therefore, positivity of NCP originated from natural infection. One HC, one DP and one KTR were identified anti-NCP positive (Figure S1).

\section{Substantially impaired serological response upon mRNA vaccination with BNT162b2 in DP and even more pronounced in KTR patients}

Antibody response to BNT162b2 was assessed in all individuals $7 \pm 2$ days after boost using the Euroimmun ELISA for the detection of IgG and IgA against the S1 domain of the SARS-CoV-2 spike. All HC seroconverted, were positive for both anti-S1 IgG and anti-S1 IgA (Fig. $1 \mathrm{~A}, \mathrm{~B}$ ), and showed SARS-CoV-2 neutralization (Fig. 1C). Anti-S1 IgA and anti-S1 IgG titers were markedly diminished $7 \pm 2$ days after boost in DP patients compared to $\mathrm{HC}$ (Fig. 1A, B). In the S1 IgG assay, $31 / 44$ (70.5\%) of the DP were positive and 30/44 (68.2\%) developed anti-S1 IgA antibodies.

Of particular interest, anti-S1 IgG and anti-S1 IgA responses were substantially diminished in KTR compared to $\mathrm{HC}$ and DP, respectively. Only one out of 40 patients (2.5\%) was positive for IgG (apparently after prior unrecognized infection) and 4 patients for IgA (10\%). Virus neutralization was observed in 30/44 (68.2\%) DP patients (Fig. 1C), while 0/40 KTR had inhibiting antiviral antibodies (Fig. 1C). Interestingly, the patient's serum with IgG and prior infection did not achieve neutralizing effects. Previously infected individuals are indicated in red in (Fig. 1A-C). Their levels of antibody and neutralization was in the range of other individuals of the respective group.

To further address the effect of age in our cohort, we divided the group into individuals $<60$ years and $>60$ years of age. HC $>60$ years showed a lower anti-S1 IgG and IgA than $\mathrm{HC}<60$ years, while their neutralization capacity was unchanged (Fig. 1D-F). DP and KTR did not show differences in anti-S1 IgG and IgA, but DP >60 exhibited a lower neutralization capacity compared to DP $<60$ years (Fig. 1D-F). DP and KTR $<60$ and $>60$ years of age showed an overall diminished anti-S1 IgG and IgA as well as neutralization capacity compared to $\mathrm{HC}<60$ and $>60$ years of age, respectively (Fig. 1DF). Anti-S1 IgG and IgA correlated with age in $\mathrm{HC}$ while this correlation was weak in DP and KTR (Figure S2).

HC showed no significant further increase of humoral response later than 28 days post initial vaccination with BNT162b2 (19). A delayed immune response might have explained the initial limited serologic response in immunocompromised individuals (DP and KTR) with mRNA vaccines. 
Therefore, we collected additional follow-up samples from KTR and DP 3-4 weeks after boost. Interestingly, anti-S1 IgG increased significantly in DP (Fig. 1G), while anti-S1 IgA and surrogate neutralization remained stable (Fig. $1 \mathrm{H})$ during the additional observation. In contrast, KTR patients did not develop additional anti-S1 IgG, anti-S1 IgA and neutralizing antibodies until the second follow-up investigation 3-4 weeks after the boost (Fig. 1G-I). In summary, KTR showed a significantly reduced serological response including lack of further increases up to 3-4 weeks after BNT162b2 boost.

\section{DP and KTR showed reduced $B$ cells numbers but simi- lar distribution among memory subsets}

B cell lymphopenia is described for DP (20) and KTR (21) and might affect proper humoral immune responses. To initially address the frequency, distribution, and phenotype of peripheral blood B cells in DP, KTR compared to HC, we analyzed the distribution of $\mathrm{B}$ cell subsets at baseline (pre-vaccination) and $7 \pm 2$ days after boost (Fig. 2A). Of interest, the frequency of CD19+ B cells was significantly diminished only in KTR compared to DP at the assessment $7 \pm 2$ days after boost and compared to $\mathrm{HC}$ at baseline, while no differences were otherwise observed (Fig. 2B). However, substantial reductions in absolute B cell counts were identified between KTR patients and $\mathrm{HC}$ at baseline as well as $\mathrm{HC}$ versus the DP and KTR cohorts, $7 \pm 2$ days after boost, respectively (Fig. 2C).

The frequency of plasmablasts among total CD19+ B cells did not differ between groups (Fig. 2D, E) at baseline and after boost. DP and KTR patients carried lower frequencies of pre-switch B cells, while KTR had an increased frequency of naïve $B$ cells before vaccination but not after vaccination. Post-switch memory B cells were higher in DP before but not after vaccination. Double negative (DN, CD27-IgD-) B cells did not differ significantly among groups (Fig. 2D,E). Interestingly, immunoglobulin isotype distribution among B cell subsets was not different among study groups (Fig. 2F,G). In summary, KTR and DP showed a characteristic reduction of absolute B cells with certain differences in the pre-memory (naive and pre-switch) but no differences within B memory compartments.

\section{Impaired induction of anti-BNT162b2 B cell and plas- mablast responses in KTR and HD patients}

In order to better understand the underlying $\mathrm{B}$ and plasma cell differentiation upon vaccine challenge, we developed a flow cytometric method to identify and quantify RBDspecific B cells in human peripheral blood. B cells (CD3-CD14-CD19+) able to bind simultaneously RBD-AF488 and RBD-AF647 were validated as antigen-specific (Fig. 3A). The specificity of RBD binding was further confirmed by blocking with unlabeled RBD prior to staining (Fig. 3A). We identified an RBD-specific clone (CDRH3: ARDYGGNANYFHY, CDRL3:QQYDNLPIT) in 3 different vaccines (HC) with highly identical amino acid sequence as reported before upon mRNA vaccinations (22). Subsequently RBD $+B$ cells were further analyzed according to their distribution among subsets and isotypes (gated as shown for general B cells in Fig. 2A,F.

Overall, an increased frequency of RBD-specific B cells among CD19+ B cells was found $7 \pm 2$ days after boost compared to baseline for HC, DP and KTR (Fig. 3B). The absolute number of antigen-specific B cells was significantly increased in $\mathrm{HC}$ at $7 \pm 2$ days after boost only in contrast to DP and KTR patients (Fig. 3C).

Subsequent analyses addressed the distribution of the RBD-specific B cells among B cell subsets (gating as seen in Fig. 2A). Most notably, a large number of $\mathrm{RBD}+\mathrm{B}$ cells were found in the plasmablast compartment in $\mathrm{HC}$, which was significantly lower in DP and KTR (Fig. 3D and Figure S3). The very limited antigen-specific B cells in KTR resided preferentially within the naïve and pre-switch compartment compared to HC (Fig. 3D and Figure S3). In contrast, antigenspecific B cells from HC were detected mainly within postswitch and double negative B cells belonging largely to the memory compartment (Fig. 3D). Consistent with impaired (not completely executed) B memory induction, the frequency of IgM RBD+ B cells (defined as IgG-IgA-) was more frequently detected in KTR and DP patients compared to HC, in whom antigen-specific IgG+ B cells dominated. The frequency of IgA+ RBD+ B cells was comparable across groups (Fig. 3E).

Two-dimension t-SNE plots clustering all RBD+ B cells according to expression patterns, analyzed with a color axis for CD27, CD38 and IgG, illustrated the notable differences between groups including the substantially reduced plasmablasts (CD27++, CD38++) and IgG expressing RBD+ B cells in the KTR cohort (Fig. 3F). In summary, KTR patients were not only characterized by a reduced overall number of antigen specific B cells, but also exhibited signatures of abnormal B cell memory formation.

\section{Unique correlation of anti-BNT162b2 serological and B cell responses}

Our earlier vaccination studies against tetanus, diphtheria and KLH (Keyhole Limpet Hemocyanin) do not reveal a typical relation between plasmablast/ B cell responses and the serologic Ig outcome $(6-8)$ in contrast to such relation for polysaccharides, such as meningococcal and pneumococcal vaccine $(23,24)$. Therefore, we wondered how the antiBNT162b2 humoral immune and B cell specific responses against an mRNA vaccine are interrelated. A correlation matrix including all groups and patients was carried out. As previously described $(25,26)$, the neutralization capacity strongly correlates with anti-S1 IgG as well as anti-S1 IgA (Fig. $4 \mathrm{~A})$. The frequency of total RBD+ cells did not correlate with anti-S1 IgG, IgA and neutralization capacity, respectively. The frequency and total number of $\mathrm{RBD}+$ plasmablasts correlated 
with all parameters of humoral response (anti-S1 IgG, anti-S1 IgA and the neutralization capacity). Age and the total number of RBD+ B cells correlated in HC, while it did not in DP and KTR (Figure S2). Subsequent analyses addressed how non-responders with a negative neutralization test $(<30 \%)$ differed from responders $(>30 \%)$. Responders and non-responders were significantly different in the frequency and number of $\mathrm{RBD}+$ plasmablasts and $\mathrm{RBD}+$ pre-switch memory $\mathrm{B}$ cells as well as in the frequency of RBD+ naïve B cells (Fig. 4B). This data suggested clear interdependence of the distinct memory B and plasmablast compartments being a characteristic of this mRNA vaccine.

\section{Diminished $T$ cell and plasmablast response in KTR}

To further understand the lack of B cell memory induction, we sorted $\mathrm{CD} 27++\mathrm{CD} 38++$ plasmablasts, CD27+CD38var memory B cells and HLA-DR+CD38+ activated $\mathrm{T}$ cells of the peripheral blood as indicators of the ongoing immune response after vaccination $(7,27)$ and generated single cell transcriptomes combined with Cellular Indexing of Transcriptomes and Epitopes by Sequencing (CITE-seq) (28) for selected surface markers (Figure S4) $7 \pm 2$ days after boost vaccination. After removal of doublets, we analyzed a total of 10796 cells. According to their transcriptomes, these cells were categorized in 7 different clusters as shown by Uniform Manifold Approximation and Projection for Dimension Reduction (UMAP) (29) (Figure S4A, B). We focused on the most abundant clusters. Four of which belong to the $\mathrm{T}$ cell compartment, with the most abundant cluster 0 having represented activated $C D 8+H L A D R+M S 4 A 1+\mathrm{T}$ cells, followed by cluster 1 which represented different types of the CD4+ T cells, including e.g., FOXP3+CD25+ regulatory T cells (Figure S4C and S5). Cluster 2 contained different populations of CD8+ T cell expressing either CD45RA or CD45RO (Figure S4B,C) and finally cluster 5 represented a $T C F 7+C D 27+G Z M K+\mathrm{T}$ cells. Cluster 6 contained proliferating cells expressing MKI67 (Figure S4B-C). Memory B cells expressing high levels of MS4A1, HLA-DRA and $C D 27$ were located in cluster 3 . Cluster 4 represented plasmablasts expressing CD27, CD38, PRDM1 and IRF4 (Figure S4B-C). Of note, the protein expression of selected surface markers detected by CITE-seq supported the classification of the 7 main clusters (Figure S5). In the selected cohort of 4 KTR, 3 did not show a serological response to the vaccination (non-responder), while one individual had detectable anti-S1 IgG antibodies but also a previously undetected infection (responder). Accordingly, the 3 non-responders had reduced frequencies of cluster 4,5 and 6 representing plasmablasts, $T C F 7+C D 27+G Z M K+\mathrm{T}$ cells and proliferating MKI67expressing lymphocytes (Figure S4D, E). CD45RO+ follicular T helper like cells expressing either IL21 or PDCDI+ could only be detected in the CD4+ T cell compartment (Cluster 1) of the non-responder \#3 and the responder (Figure S4F).
Interestingly, the majority of memory B cells (cluster 3 ) of the responder expressed ITGAX (gene encoding for CD11c), while this subpopulation in cluster 3 was almost absent in the nonresponders (Figure S4F).

\section{DISCUSSION}

SARS-CoV-2 mRNA vaccines are highly protective against COVID-19 $(2,30)$, while it is not yet clear how these vaccines induce and maintain B cell memory responses among immunocompromised patients. Available data show a durable humoral response and B cell response $(31,32)$ in healthy individuals and also elderly patients $(2,19)$. Moreover, mRNA vaccines are reported to induce germinal center (GC) responses in mice and are expected to result in lasting plasma cell responses (33). Here, we investigated the distribution of anti-BNT162b2 antigen-specific B cell responses among HC in comparison to DP and KTR as prototypes for differentially immunocompromised patients. An assay for the detection of RBD-specific B lineage cells has been developed with high specificity based on our prior experiences for the detection of antigen-specific B cells and plasmablasts (i.e., tetanus, KLH, pentraxin $(8,34))$. Specificity was proven by appropriate blocking experiments and identification of an RBD-specific clone (CDRH3) among RBD++ B cells, which was found in 3 different vaccines (HC) with highly identical amino acid sequence immunized as reported very recently upon mRNA vaccinations (22). Of particular interest, seroconversion and the induction of neutralizing antibodies upon BNT1622b vaccination was very robust and similar in our cohort in $\mathrm{HC}$ as observed by prior studies (2). In these HC, we also found a typical formation of antigen-specific plasmablasts and postswitch memory B cells upon vaccination boost which was comparable to frequencies of tetanus-specific B cells after booster vaccination (35). Thus, the findings among HC provide a valid comparison with the two patient cohorts.

Among DP and KTR, we observed a markedly diminished generation of antigen-specific B cells, especially within major effector compartments of protective B cell immunity, namely plasmablasts and memory B cells. Consistently, lower IgG+ anti-RBD cells were found related to impaired induction of a vaccine response. This was accompanied by a low rate of seroconversion of DP on day $7 \pm 2$ that somewhat improved 34 weeks after vaccination, while this could not be compared to $\mathrm{HC}$ in our cohort due to a missing follow-up. In the KTR cohort, the rate of serological and cellular response was almost absent with only one patient who developed specific anti-S1 IgG but apparently based on a prior unrecognized infection and likely reflecting a further boost underlining the potential effectiveness of optimized vaccines or vaccination protocols. Interestingly, no KTR patient exhibited a positive neutralization at day $7 \pm 2$ after boost including the patient with positive IgG titers. At a further follow up 3-4 weeks after boost, no seroconversions were found in KTR. These data are 
in contrast to recently published data of Boyarsky et al. who described a seroconversion in 23/223 (10.35\%) of KTR vaccinated with BNT162b2 already after the first dose (5). As a limitation of our study, we only have a limited sample size as well as a very uniform immunosuppressive regimen of KTR, which does not allow for a firm conclusion which immunosuppressant may cause the impaired immune response. For DP patients, seroconversion rates of about $90 \%$ after two doses have been described which is similar to the findings in our cohort $(4,36)$.

The large discrepancy of the serological response and impaired B cell response in our KTR cohort raises the question about which factors or mechanism are involved. Incorrect handling of the sensitive mRNA vaccine can be excluded since the same mRNA vaccine of the same lot induced a favorable response among DP patients. The major difference between KTR and DP/HC appeared to be the almost uniform immunosuppressive therapy with MMF, CNI and glucocorticoids among the KTR patients, although the individual impact of MMF, cyclosporine vs. tacrolimus and glucocorticoids needs to be further delineated. CNI and MMF directly inhibit activation and proliferation of CD4+ T cells, Tfh cells and $\mathrm{B}$ cells (37-41). In this regard, single cell transcriptomes and CITE-seq analyses identified substantial differences between the vaccine responder and three non-responders within the KTR cohort. Namely plasmablasts, TCF7+CD27+GZMK+ T cells and proliferating MKI67-expressing lymphocytes were increased in the responders suggesting that these three subsets are key drivers of a successful BNT162b2 response.

Three individuals with likely prior asymptomatic virus exposure (each in HC, DP and KTR cohorts) were identified by preexisting antibodies against viral NC. Interestingly, they did not show notable differences in vaccine response compared to their cohorts, with the exception of one seroconversion in the KTR. A number of recent studies report that a first vaccination in previously infected individuals acts as a boost that leads to higher antibody levels than individuals vaccinated twice with an mRNA vaccine. It further does not change isotype distribution among memory B cells (32, 42, 43). After a natural COVID-19 infection the numbers of RBDspecific memory B cells of healthy individuals are similar to those of patients who recovered from natural COVID-19 infection, while levels of anti-S1 and anti-RBD IgG are significantly higher in vaccinated individuals (44). Interestingly, the clonality of IGLV genes among RBD+ is very comparable between natural infection and the mRNA vaccination (44). At the moment it is not known whether the magnitude of antibody levels or the presence or magnitude of a $\mathrm{T}$ cell response, or both, correlate with the protection against symptomatic COVID-19. However, after natural COVID-19 infection the presence of anti-spike antibodies protects from recurrent infection, while a previous infection without detectable antibodies does not (45). Initial observational data from Israel indicate that $\mathrm{CKD}$ as well as immunosuppression have a negative impact on vaccine efficacy (46), which indicates that impaired B cell memory also results in diminished protection.

Interestingly, we found a unique relationship between plasmablast response and Ig titers which is not seen in tetanus and KLH vaccination (6-8) and is only described for polysaccharide and protein-polysaccharide conjugate vaccinations (47). Polysaccharide vaccines in contrast to mRNA vaccines induce certain serological responses following vaccination in KTR (48) which possibly relates to T independent responses. In this context, our single cell analysis confirmed a diminished plasmablast induction in the non-responders (KTR) but importantly also lack of proper CD4 and CD8 $\mathrm{T}$ cell activation. In the responder, classical signs of vaccine response with simultaneous $\mathrm{B}$ and $\mathrm{T}$ cell activation occurred but insufficient to induce neutralizing antibody titers. KTR have to be considered as a patient group who remains vulnerable to SARS-CoV-2 infection, even if vaccinated with the currently established BNT162b2 vaccination scheme.

In summary, we described a diminished humoral response to BNT162b2 as well as lack of appropriate memory formation including RBD-specific plasmablasts and postswitch memory B cells in DP and KTR. DP were able to further mature their antibody response in contrast to KTR. As such, optimized vaccination strategies especially for KTR patients are needed to achieve adequate antiviral protection.

\section{MATERIALS AND METHODS}

\section{Study design}

The study was designed to investigate the sero-response (anti-S1 IgA, anti-S1 IgG levels and neutralization test) and B cell memory formation in DP and KTR after vaccination with BNT162b2. HC, KTR and DP were vaccinated with BNT162b2 21 days apart. Baseline blood was drawn to identify previously infected individual (NCP ELISA, anti-S1 IgA, anti-S1 IgG levels) and access baseline B cell phenotype of HC, DP and KTR (flow-cytometry). To investigate the plasmablast response peripheral blood samples were obtained $7 \pm 2$ days after boost vaccination. B cell subtypes as well antigen-specific B cells were analyzed by flow-cytometry. Seroresponse was investigated $7 \pm 2$ days (HC, DP, KTR) and 3-4 weeks after the second dose (DP, KTR).

\section{Study participants}

Peripheral blood samples (EDTA anti-coagulated or serum-tubes, BD Vacutainersystem, BD Diagnostics, Franklin Lakes, NJ, USA) from 35 healthy controls, 40 hemodialysis patients, 4 peritoneal dialysis patients and 40 kidney transplant recipients were collected at $7 \pm 2$ days after the second dose of SARS-CoV-2 BNT162b2 vaccination. Individuals of KTR and DP are in part also represented in published 
manuscripts (serological response only) $(49,50)$. Material before vaccination was available for 19 healthy controls, 21 hemodialysis patients, 2 peritoneal dialysis patients, and 28 kidney transplant recipients, while a follow up after 3-4 weeks after boost is available for currently for 26 KTR and 37 DP. Donor information is summarized in Table 1. All participants gave written informed consent according to the approval of the ethics committee at the Charite University Hospital Berlin (EA2/010/21, EA4/188/20), the ethics committee of Saxony-Anhalt (EA7/21) and the ethics committee of the University of Greifswald (BB019/21).

\section{Sample processing and isolation of peripheral blood mononuclear cells (PBMCs) and staining}

Serum tubes were centrifuged at 3000rpm for $10 \mathrm{~min}$ to separate plasma. Serum was stored at -20C for antibody analysis. PBMCs were prepared by density gradient centrifugation using Ficoll-Paque PLUS (GE Healthcare Bio-Sciences, Chicago, IL, USA). For staining 1-3 $\times 10^{6}$ cells were suspended in $50 \mu \mathrm{l}$ of PBS/0.5\% BSA/EDTA and $10 \mu \mathrm{l}$ Brilliant Buffer (BD Horizon, San Jose, CA, USA. Cells were stained for 15 min on ice and washed afterwards with PBS Dulbecco containing 1\% FCS (fetal calf serum, Biowest, Nuaillé, France) ( 810 xg, 8 min, $4^{\circ} \mathrm{C}$ ). Flow cytometric analysis was performed as indicated in the Figs. 1-4.

\section{Flow cytometry}

All flow cytometry analyses were performed using a BD FACS Fortessa (BD Biosciences, Franklin Lakes, NJ, USA). To ensure comparable mean fluorescence intensities (MFIs) over time of the analyses, Cytometer Setup and Tracking beads (CST beads, BD Biosciences, Franklin Lakes, NJ, USA) and Rainbow Calibration Particles (BD Biosciences, Franklin Lakes, NJ, USA) were used. For flow cytometric analysis, the following fluorochrome-labeled antibodies were used: BUV737 anti-CD11c (BD, clone B-ly6, 1:50), BUV395 anti-CD14 (BD, clone M5E2, 1:50), BUV395 anti-CD3 (BD, clone UCHT1, 1:50), BV786 anti-CD27 (BD, clone L128, 1:50), BV711 antiCD19 (BD, clone SJ25C1,1:25), BV605 anti-CD24 (BD, clone ML5, 1:50), BV510 anti-CD10 (BD, clone HI10A, 1:20), BV421 anti-CXCR5 (BD, clone RF8B2, 1:20), PE-Cy7 anti-CD95 (ThermoFischer, Waltham, MA, USA clone APO-1/Fas, 1:100), PECF594 anti-IgD (Biolegend, San Diego, CA, USA, clone IA6-2, 1:5000), APC-Cy7 anti-CD38 (Biolegend, clone HIT2, 1:1000), PE-Cy7 anti-IgG (BD, clone G18-145, 1:1000), anti-IgA-Biotin (BD, clone G20-359, 1:50), BV650 anti-IgM (BD, clone MHM88, 1:50), FITC anti-HLA-DR (Biolegend, clone L234, 1:25), PE anti-CD21 (BD, clone B-ly4, 1:25), APC anti-CD22 (BD, clone S-HCL-1, 1:25). Siglec-1 (CD169, 1:25) expression analysis on CD14+ monocytes was performed at baseline and at the follow-up time-point as previously described (11). Number of absolute B cells was measured with Trucount (BD) and samples were processed according to the manufacturer's instruction.

\section{Staining of antigen-specific $B$ cells}

To identify RBD-specific B cells, recombinant purified RBD (DAGC149, Creative Diagnostics, New York, USA) was labeled with either AF647 or AF488. Double positive cells were considered as antigen-specific (Fig. 3). Antigens were labeled at the German Rheumatism Research Centre (DRFZ), Berlin with NHS esters conjugation for AF647 and AF488. A blocking experiment using unlabeled RBD in 100-fold concentration was used to ensure specificity of the staining (Fig. $3 \mathrm{~A})$. The number of recorded antigen-specific events ranged from 0-422 events. To ensure the specificity of our RBDspecific flow cytometric staining, we labeled memory B cells with fluorescently the two RBD and isolated them cytometrically. The isolated B cells were analyzed for their transcriptome and B cell receptor sequence using DropSeq (10X genomics). We were able to intercept and examine 168 cells from 8 vaccinated individuals 7 days after secondary immunization. This population of RBD-specific memory B cells was found to employ VDJ gene rearrangements using preferentially certain IgHV segments (IGHV3-30, IGHV3-53 and IGH3-23) and IGKV genes (IGKV1-39, IGKV1-33, IGKV1-9, and IGLV3-21) after mRNA inoculation, as described in Wang et al. (22). Most importantly, we even identified an RBDspecific clone (CDRH3: ARDYGGNANYFHY, CDRL3:QQYDNLPIT), which was found in 3 different vaccinees with highly identical amino acid sequence immunized as reported very recently upon Biontech or Moderna vaccinations (22).

\section{Enzyme-linked immunosorbent assay (Euroimmun)}

The Euroimmun anti-SARS-CoV-2 assay is a classical enzyme-linked immunosorbent assay (ELISA) for the detection of IgG to the S1 domain of the SARS-CoV-2 spike (S) protein, IgA to the $\mathrm{S} 1$ domain of the SARS-CoV-2 spike protein, and IgG to the SARS-CoV-2 NCP protein. The assay was performed according to the manufacturer's instructions and as described previously $(25,26)$.

\section{Surrogate SARS-CoV-2 neutralization test (GenScript)}

This blocking ELISA qualitatively detects anti-SARS-CoV2 antibodies suppressing the interaction between the receptor binding domain (RBD) of the viral spike glycoprotein (S) and the angiotensin-converting enzyme 2 (ACE2) protein on the surface of cells. The assay was performed according to the manufacturer's instructions and as described previously (25, 26).

\section{Single Cell RNA sequencing}

Peripheral blood Cells were enriched from peripheral blood using StraightFrom Whole Blood CD19, CD3 and CD138 MicroBeads (Miltenyi Biotec) according to manufacturer's instructions. Afterwards cell were stained, incubated with TotalSeq oligomer-conjugated hashtag antibodies ((TotalSeq-C anti-human Hashtag antibody 1 to 4 ) and sorted with a 
MA900 Multi-Application Cell Sorter (Sony Biotechnology).

Sorted populations were identified as plasmablasts (DAPI-CD3-CD14-CD16-CD38++CD27++), memory B cells (DAPI-CD3-CD14-CD16-CD38varCD27+) and activated T cells (DAPI-CD3+CD14-CD16-CD38+HLA-DR+). The three sorted populations were pooled in equal proportions and further processed for single cell RNA sequencing. Single Cell RNAlibrary preparation and sequencing, single-cell transcriptome sequencing as well as well as data analysis and statistics has been performed as previously described (51). All details can additionally be found in the supplementary materials.

\section{Data Analysis and Statistics}

All details can be found in the supplementary materials.

\section{SUPPLEMENTARY MATERIALS}

immunology.sciencemag.org/cgi/content/full/6/60/eabj1031/DC1

Supplementary Materials and Methods

Figs. S1 to S5

Table S1

\section{REFERENCES AND NOTES}

1. L. B. Hilbrands, R. Duivenvoorden, P. Vart, C. F. M. Franssen, M. H. Hemmelder, K. J. Jager, L. M. Kieneker, M. Noordzij, M. J. Pena, H. Vries, D. Arroyo, A. Covic, M. Crespo, E. Goffin, M. Islam, Z. A. Massy, N. Montero, J. P. Oliveira, A. Roca Muñoz, J. E. Sanchez, S. Sridharan, R. Winzeler, R. T. Gansevoort; ERACODA Collaborators, COVID-19-related mortality in kidney transplant and dialysis patients: Results of the ERACODA collaboration. Nephrol. Dial. Transplant. 35, 1973-1983 (2020). doi:10.1093/ndt/gfaa261 Medline

2. F. P. Polack, S. J. Thomas, N. Kitchin, J. Absalon, A. Gurtman, S. Lockhart, J. L. Perez, G. Pérez Marc, E. D. Moreira, C. Zerbini, R. Bailey, K. A. Swanson, S. Roychoudhury, K. Koury, P. Li, W. V. Kalina, D. Cooper, R. W. Frenck Jr., L. L. Hammitt, Ö. Türeci, H. Nell, A. Schaefer, S. Ünal, D. B. Tresnan, S. Mather, P. R. Dormitzer, U. Şahin, K. U. Jansen, W. C. Gruber; C4591001 Clinical Trial Group, Safety and Efficacy of the BNT162b2 mRNA Covid-19 Vaccine. N. Engl. J. Med. 383, 2603-2615 (2020). doi:10.1056/NEJMoa2034577 Medline

3. N. Dagan, N. Barda, E. Kepten, O. Miron, S. Perchik, M. A. Katz, M. A. Hernán, M. Lipsitch, B. Reis, R. D. Balicer, BNT162b2 mRNA Covid-19 Vaccine in a Nationwide Mass Vaccination Setting. N. Engl. J. Med. 384, 1412-1423 (2021). doi:10.1056/NEJMoa2101765 Medline

4. B. Simon, H. Rubey, A. Treipl, M. Gromann, B. Hemedi, S. Zehetmayer, B. Kirsch, Hemodialysis Patients Show a Highly Diminished Antibody Response after COVID19 mRNA Vaccination Compared to Healthy Controls. medRxiv, 2021.2003.2026.21254259 (2021).

5. B. J. Boyarsky, W. A. Werbel, R. K. Avery, A. A. R. Tobian, A. B. Massie, D. L. Segev, J. M. Garonzik-Wang, Immunogenicity of a Single Dose of SARS-CoV-2 Messenger RNA Vaccine in Solid Organ Transplant Recipients. JAMA 325, 1784-1786 (2021). Medline

6. H. Leyendeckers, M. Odendahl, A. Löhndorf, J. Irsch, M. Spangfort, S. Miltenyi, N. Hunzelmann, M. Assenmacher, A. Radbruch, J. Schmitz, Correlation analysis between frequencies of circulating antigen-specific IgG-bearing memory B cells and serum titers of antigen-specific IgG. Eur. J. Immunol. 29, 1406-1417 (1999). doi:10.1002/(SICl)1521-4141(199904)29:04<1406:AID-IMMU1406>3.0.CO:2-P Medline

7. M. Odendahl, H. Mei, B. F. Hoyer, A. M. Jacobi, A. Hansen, G. Muehlinghaus, C. Berek, F. Hiepe, R. Manz, A. Radbruch, T. Dörner, Generation of migratory antigenspecific plasma blasts and mobilization of resident plasma cells in a secondary immune response. Blood 105, 1614-1621 (2005). doi:10.1182/blood-2004-072507 Medline

8. C. Giesecke, T. Meyer, P. Durek, J. Maul, J. Preiß, J. F. M. Jacobs, A. Thiel, A. Radbruch, R. Ullrich, T. Dörner, Simultaneous Presence of Non- and Highly Mutated Keyhole Limpet Hemocyanin (KLH)-Specific Plasmablasts Early after Primary KLH Immunization Suggests Cross-Reactive Memory B Cell Activation. J.
Immunol. 200, 3981-3992 (2018). doi:10.4049/iimmunol.1701728 Medline

9. M. Syed-Ahmed, M. Narayanan, Immune Dysfunction and Risk of Infection in Chronic Kidney Disease. Adv. Chronic Kidney Dis. 26, 8-15 (2019). doi:10.1053/i.ackd.2019.01.004 Medline

10. S. Kato, M. Chmielewski, H. Honda, R. Pecoits-Filho, S. Matsuo, Y. Yuzawa, A. Tranaeus, P. Stenvinkel, B. Lindholm, Aspects of immune dysfunction in endstage renal disease. Clin. J. Am. Soc. Nephrol. 3, 1526-1533 (2008). doi:10.2215/CJN.00950208 Medline

11. M. G. Betjes, Immune cell dysfunction and inflammation in end-stage renal disease. Nat. Rev. Nephrol. 9, 255-265 (2013). doi:10.1038/nrneph.2013.44 Medline

12. W. R. Mulley, S. T. Le, K. E. Ives, Primary seroresponses to double-dose compared with standard-dose hepatitis B vaccination in patients with chronic kidney disease: A systematic review and meta-analysis. Nephrol. Dial. Transplant. 32, 136-143 (2017). Medline

13. Z. Liao, X. Xu, Y. Liang, Y. Xiong, R. Chen, J. Ni, Effect of a booster dose of influenza vaccine in patients with hemodialysis, peritoneal dialysis and renal transplant recipients: A systematic literature review and meta-analysis. Hum. Vaccin. Immunother. 12, 2909-2915 (2016). doi:10.1080/21645515.2016.1201623 Medline

14. L. B. Rodda, J. Netland, L. Shehata, K. B. Pruner, P. A. Morawski, C. D. Thouvenel, K. K. Takehara, J. Eggenberger, E. A. Hemann, H. R. Waterman, M. L. Fahning, Y. Chen, M. Hale, J. Rathe, C. Stokes, S. Wrenn, B. Fiala, L. Carter, J. A. Hamerman, N. P. King, M. Gale Jr., D. J. Campbell, D. J. Rawlings, M. Pepper, Functional SARSCoV-2-Specific Immune Memory Persists after Mild COVID-19. Cell 184, 169183.e17 (2021). doi:10.1016/i.cell.2020.11.029 Medline

15. G. E. Hartley, E. S. J. Edwards, P. M. Aui, N. Varese, S. Stojanovic, J. McMahon, A. Y. Peleg, I. Boo, H. E. Drummer, P. M. Hogarth, R. E. O'Hehir, M. C. van Zelm, Rapid generation of durable B cell memory to SARS-CoV-2 spike and nucleocapsid proteins in COVID-19 and convalescence. Sci. Immunol. 5, eabf8891 (2020). doi:10.1126/sciimmunol.abf8891 Medline

16. J. M. Dan, J. Mateus, Y. Kato, K. M. Hastie, E. D. Yu, C. E. Faliti, A. Grifoni, S. I. Ramirez, S. Haupt, A. Frazier, C. Nakao, V. Rayaprolu, S. A. Rawlings, B. Peters, F. Krammer, V. Simon, E. O. Saphire, D. M. Smith, D. Weiskopf, A. Sette, S. Crotty, Immunological memory to SARS-CoV-2 assessed for up to 8 months after infection. Science 371, eabf4063 (2021). doi:10.1126/science.abf4063 Medline

17. E. D. O'Sullivan, J. S. Lees, K. L. Howie, D. Pugh, K. A. Gillis, J. P. Traynor, I. Macintyre, P. B. Mark, Prolonged SARS-CoV-2 viral shedding in patients with chronic kidney disease. Nephrology (Carlton) 26, 328-332 (2021). $\frac{\text { doi:10.1111/nep. } 13844 \text { Medline }}{\text { B }}$

18. B. Bikbov, N. Perico, G. Remuzzi; on behalf of the GBD Genitourinary Diseases Expert Group, Disparities in Chronic Kidney Disease Prevalence among Males and Females in 195 Countries: Analysis of the Global Burden of Disease 2016 Study. Nephron 139, 313-318 (2018). doi:10.1159/000489897 Medline

19. U. Sahin, A. Muik, E. Derhovanessian, I. Vogler, L. M. Kranz, M. Vormehr, A. Baum, K. Pascal, J. Quandt, D. Maurus, S. Brachtendorf, V. Lörks, J. Sikorski, R. Hilker, D. Becker, A. K. Eller, J. Grützner, C. Boesler, C. Rosenbaum, M. C. Kühnle, U. Luxemburger, A. Kemmer-Brück, D. Langer, M. Bexon, S. Bolte, K. Karikó, T. Palanche, B. Fischer, A. Schultz, P. Y. Shi, C. Fontes-Garfias, J. L. Perez, K. A. Swanson, J. Loschko, I. L. Scully, M. Cutler, W. Kalina, C. A. Kyratsous, D. Cooper, P. R. Dormitzer, K. U. Jansen, Ö. Türeci, COVID-19 vaccine BNT162b1 elicits human antibody and $T_{H} 1 \mathrm{~T}$ cell responses. Nature 586, 594-599 (2020). doi:10.1038/s41586-020-2814-7 Medline

20. M. Molina, L. M. Allende, L. E. Ramos, E. Gutiérrez, D. E. Pleguezuelo, E. R. Hernández, F. Ríos, C. Fernández, M. Praga, E. Morales, CD19+ B-Cells, a New Biomarker of Mortality in Hemodialysis Patients. Front. Immunol. 9, 1221 (2018). doi:10.3389/fimmu.2018.01221 Medline

21. V. Svachova, A. Sekerkova, P. Hruba, I. Tycova, M. Rodova, E. Cecrdlova, J. Slatinska, E. Honsova, I. Striz, O. Viklicky, Dynamic changes of B-cell compartments in kidney transplantation: Lack of transitional B cells is associated with allograft rejection. Transpl. Int. 29, 540-548 (2016). doi:10.1111/tri.12751 Medline

22. Z. Wang, F. Schmidt, Y. Weisblum, F. Muecksch, C. O. Barnes, S. Finkin, D. Schaefer-Babajew, M. Cipolla, C. Gaebler, J. A. Lieberman, T. Y. Oliveira, Z. Yang, M. E. Abernathy, K. E. Huey-Tubman, A. Hurley, M. Turroja, K. A. West, K. Gordon, 
K. G. Millard, V. Ramos, J. Da Silva, J. Xu, R. A. Colbert, R. Patel, J. Dizon, C. UnsonO'Brien, I. Shimeliovich, A. Gazumyan, M. Caskey, P. J. Bjorkman, R. Casellas, T. Hatziioannou, P. D. Bieniasz, M. C. Nussenzweig, mRNA vaccine-elicited antibodies to SARS-CoV-2 and circulating variants. Nature 592, 616-622 (2021). doi:10.1038/s41586-021-03324-6 Medline

23. G. Blanchard-Rohner, M. D. Snape, D. F. Kelly, D. O'Connor, T. John, E. A. Clutterbuck, B. Ohene-Kena, C. L. Klinger, T. Odrljin, A. J. Pollard, The B-cell response to a primary and booster course of MenACWY-CRM(1)(9)(7) vaccine administered at 2, 4 and 12 months of age. Vaccine 31, 2441-2448 (2013). doi:10.1016/i.vaccine.2013.03.036 Medline

24. D. O'Connor, E. A. Clutterbuck, A. J. Thompson, M. D. Snape, M. N. Ramasamy, D. F. Kelly, A. J. Pollard, High-dimensional assessment of B-cell responses to quadrivalent meningococcal conjugate and plain polysaccharide vaccine. Genome Med. 9,11 (2017). doi:10.1186/s13073-017-0400-x Medline

25. B. Jahrsdörfer, J. Kroschel, C. Ludwig, V. M. Corman, T. Schwarz, S. Körper, M. Rojewski, R. Lotfi, C. Weinstock, C. Drosten, E. Seifried, T. Stamminger, H. J. Groß, $\mathrm{H}$. Schrezenmeier, Independent Side-by-Side Validation and Comparison of 4 Serological Platforms for SARS-CoV-2 Antibody Testing. J. Infect. Dis. 223, 796801 (2021). doi:10.1093/infdis/jiaa656 Medline

26. B. Jahrsdörfer, R. Groß, A. Seidel, L. Wettstein, C. Ludwig, T. Schwarz, S. Körper, M. Rojewski, R. Lotfi, C. Weinstock, E. Seifried, V. M. Corman, C. Drosten, J. Münch, H. Schrezenmeier, Characterization of the SARS-CoV-2 Neutralization Potential of COVID-19-Convalescent Donors. J. Immunol. 206, 2614-2622 (2021). doi:10.4049/jimmunol.2100036 Medline

27. J. D. Miller, R. G. van der Most, R. S. Akondy, J. T. Glidewell, S. Albott, D. Masopust, K. Murali-Krishna, P. L. Mahar, S. Edupuganti, S. Lalor, S. Germon, C. Del Rio, M. J. Mulligan, S. I. Staprans, J. D. Altman, M. B. Feinberg, R. Ahmed, Human effector and memory CD8+ T cell responses to smallpox and yellow fever vaccines. Immunity 28, 710-722 (2008). doi:10.1016/i.immuni.2008.02.020 Medline

28. M. Stoeckius, C. Hafemeister, W. Stephenson, B. Houck-Loomis, P. K. Chattopadhyay, H. Swerdlow, R. Satija, P. Smibert, Simultaneous epitope and transcriptome measurement in single cells. Nat. Methods 14, 865-868 (2017). doi:10.1038/nmeth.4380 Medline

29. E. Becht, L. Mclnnes, J. Healy, C. A. Dutertre, I. W. H. Kwok, L. G. Ng, F. Ginhoux, E. W. Newell, Dimensionality reduction for visualizing single-cell data using UMAP. Nat. Biotechnol. (2018). Medline

30. L. R. Baden, H. M. El Sahly, B. Essink, K. Kotloff, S. Frey, R. Novak, D. Diemert, S. A. Spector, N. Rouphael, C. B. Creech, J. McGettigan, S. Khetan, N. Segall, J. Solis, A. Brosz, C. Fierro, H. Schwartz, K. Neuzil, L. Corey, P. Gilbert, H. Janes, D. Follmann, M. Marovich, J. Mascola, L. Polakowski, J. Ledgerwood, B. S. Graham, H. Bennett, R. Pajon, C. Knightly, B. Leav, W. Deng, H. Zhou, S. Han, M. Ivarsson, J. Miller, T. Zaks; COVE Study Group, Efficacy and Safety of the mRNA-1273 SARSCoV-2 Vaccine. N. Engl. J. Med. 384, 403-416 (2021). doi:10.1056/NEJMoa2035389 Medline

31. A. T. Widge, N. G. Rouphael, L. A. Jackson, E. J. Anderson, P. C. Roberts, M. Makhene, J. D. Chappell, M. R. Denison, L. J. Stevens, A. J. Pruijssers, A. B. McDermott, B. Flach, B. C. Lin, N. A. Doria-Rose, S. O'Dell, S. D. Schmidt, K. M. Neuzil, H. Bennett, B. Leav, M. Makowski, J. Albert, K. Cross, V. V. Edara, K. Floyd, M. S. Suthar, W. Buchanan, C. J. Luke, J. E. Ledgerwood, J. R. Mascola, B. S. Graham, J. H. Beigel; mRNA-1273 Study Group, Durability of Responses after SARS-CoV-2 mRNA-1273 Vaccination. N. Engl. J. Med. 384, 80-82 (2021). doi:10.1056/NEJMc2032195 Medline

32. R. R. Goel, S. A. Apostolidis, M. M. Painter, D. Mathew, A. Pattekar, O. Kuthuru, S. Gouma, P. Hicks, W. Meng, A. M. Rosenfeld, S. Dysinger, K. A. Lundgreen, L. KuriCervantes, S. Adamski, A. Hicks, S. Korte, D. A. Oldridge, A. E. Baxter, J. R. Giles, M. E. Weirick, C. M. McAllister, J. Dougherty, S. Long, K. D’Andrea, J. T. Hamilton, M. R. Betts, E. T. Luning Prak, P. Bates, S. E. Hensley, A. R. Greenplate, E. J. Wherry, Distinct antibody and memory B cell responses in SARS-CoV-2 naïve and recovered individuals following mRNA vaccination. Sci. Immunol. 6, eabi6950 (2021). doi:10.1126/sciimmunol.abi6950 Medline

33. K. Lederer, D. Castaño, D. Gómez Atria, T. H. Oguin 3rd, S. Wang, T. B. Manzoni, H. Muramatsu, M. J. Hogan, F. Amanat, P. Cherubin, K. A. Lundgreen, Y. K. Tam, S. H. Y. Fan, L. C. Eisenlohr, I. Maillard, D. Weissman, P. Bates, F. Krammer, G. D. Sempowski, N. Pardi, M. Locci, SARS-CoV-2 mRNA Vaccines Foster Potent Antigen-Specific Germinal Center Responses Associated with Neutralizing
Antibody Generation. Immunity 53, 1281-1295.e5

(2020). doi:10.1016/j.immuni.2020.11.009 Medline

34. M. Gatto, A. Wiedemann, N. Nomovi, K. Reiter, E. Schrezenmeier, T. Rose, F. Szelinski, A. C. Lino, S. Valentino, A. Ghirardello, T. Dörner, A. Doria, Circulating Pentraxin3-Specific B Cells Are Decreased in Lupus Nephritis. Front. Immunol. 10, 29 (2019). doi:10.3389/fimmu.2019.00029 Medline

35. D. Frölich, C. Giesecke, H. E. Mei, K. Reiter, C. Daridon, P. E. Lipsky, T. Dörner, Secondary immunization generates clonally related antigen-specific plasma cells and memory B cells. J. Immunol. 185, 3103-3110 (2010). doi:10.4049/iimmunol.1000911 Medline

36. A. Grupper, N. Sharon, T. Finn, R. Cohen, M. Israel, A. Agbaria, Y. Rechavi, I. F. Schwartz, D. Schwartz, Y. Lellouch, M. Shashar, Humoral Response to the Pfizer BNT162b2 Vaccine in Patients Undergoing Maintenance Hemodialysis. Clin. J. Am. Soc. Nephrol. CJN.03500321 (2021). doi:10.2215/CJN.03500321 Medline

37. K. Kogina, H. Shoda, Y. Yamaguchi, N. H. Tsuno, K. Takahashi, K. Fujio, K. Yamamoto, Tacrolimus differentially regulates the proliferation of conventional and regulatory CD4(+) T cells. Mol. Cells 28, 125-130 (2009). doi:10.1007/s10059-009-0114-z Medline

38. E. F. Wallin, D. L. Hill, M. A. Linterman, K. J. Wood, The Calcineurin Inhibitor Tacrolimus Specifically Suppresses Human T Follicular Helper Cells. Front. Immunol. 9, 1184 (2018). doi:10.3389/fimmu.2018.01184 Medline

39. S. U. Sankatsing, J. M. Prins, S. L. Yong, J. Roelofsen, A. B. van Kuilenburg, S. Kewn, D. J. Back, F. J. Bemelman, I. J. ten Berge, Mycophenolate mofetil inhibits T-cell proliferation in kidney transplant recipients without lowering intracellular dGTP and GTP. Transpl. Int. 21, 1066-1071 (2008). doi:10.1111/i.14322277.2008.00739.x Medline

40. J. L. Karnell, F. G. Karnell 3rd, G. L. Stephens, B. Rajan, C. Morehouse, Y. Li, B. Swerdlow, M. Wilson, R. Goldbach-Mansky, C. Groves, A. J. Coyle, R. Herbst, R. Ettinger, Mycophenolic acid differentially impacts B cell function depending on the stage of differentiation. J. Immunol. 187, 3603-3612 (2011). doi:10.4049/iimmunol.1003319 Medline

41. O. Traitanon, J. M. Mathew, G. La Monica, L. Xu, V. Mas, L. Gallon, Differential Effects of Tacrolimus versus Sirolimus on the Proliferation, Activation and Differentiation of Human B Cells. PLOS ONE 10, e0129658 (2015). doi:10.1371/journal.pone.0129658 Medline

42. C. Manisty, A. D. Otter, T. A. Treibel, Á. McKnight, D. M. Altmann, T. Brooks, M. Noursadeghi, R. J. Boyton, A. Semper, J. C. Moon, Antibody response to first BNT162b2 dose in previously SARS-CoV-2-infected individuals. Lancet 397 , 1057-1058 (2021). doi:10.1016/S0140-6736(21)00501-8 Medline

43. F. Krammer, K. Srivastava, H. Alshammary, A. A. Amoako, M. H. Awawda, K. F. Beach, M. C. Bermúdez-González, D. A. Bielak, J. M. Carreño, R. L. Chernet, L. Q. Eaker, E. D. Ferreri, D. L. Floda, C. R. Gleason, J. Z. Hamburger, K. Jiang, G. Kleiner, D. Jurczyszak, J. C. Matthews, W. A. Mendez, I. Nabeel, L. C. F. Mulder, A. J. Raskin, K. T. Russo, A. T. Salimbangon, M. Saksena, A. S. Shin, G. Singh, L. A. Sominsky, D. Stadlbauer, A. Wajnberg, V. Simon, Antibody Responses in Seropositive Persons after a Single Dose of SARS-CoV-2 mRNA Vaccine. N. Engl. J. Med. 384, 1372-1374 (2021). doi:10.1056/NEJMc2101667 Medline

44. Z. Wang, F. Schmidt, Y. Weisblum, F. Muecksch, C. O. Barnes, S. Finkin, D. Schaefer-Babajew, M. Cipolla, C. Gaebler, J. A. Lieberman, T. Y. Oliveira, Z. Yang, M. E. Abernathy, K. E. Huey-Tubman, A. Hurley, M. Turroja, K. A. West, K. Gordon, K. G. Millard, V. Ramos, J. Da Silva, J. Xu, R. A. Colbert, R. Patel, J. Dizon, C. UnsonO'Brien, I. Shimeliovich, A. Gazumyan, M. Caskey, P. J. Bjorkman, R. Casellas, T. Hatziioannou, P. D. Bieniasz, M. C. Nussenzweig, mRNA vaccine-elicited antibodies to SARS-CoV-2 and circulating variants. Nature 592, 616-622 (2021). doi:10.1038/s41586-021-03324-6 Medline

45. S. F. Lumley, D. O'Donnell, N. E. Stoesser, P. C. Matthews, A. Howarth, S. B. Hatch, B. D. Marsden, S. Cox, T. James, F. Warren, L. J. Peck, T. G. Ritter, Z. de Toledo, L. Warren, D. Axten, R. J. Cornall, E. Y. Jones, D. I. Stuart, G. Screaton, D. Ebner, S. Hoosdally, M. Chand, D. W. Crook, A. M. O'Donnell, C. P. Conlon, K. B. Pouwels, A. S. Walker, T. E. A. Peto, S. Hopkins, T. M. Walker, K. Jeffery, D. W. Eyre; Oxford University Hospitals Staff Testing Group, Antibody Status and Incidence of SARSCoV-2 Infection in Health Care Workers. N. Engl. J. Med. 384, 533-540 (2021). doi:10.1056/NEJMoa2034545 Medline

46. I. Yelin, R. Katz, E. Herzel, T. Berman-Zilberstein, A. Ben-Tov, J. Kuint, S. Gazit, T. Patalon, G. Chodick, R. Kishony, Associations of the BNT162b2 COVID-19 vaccine 
effectiveness with patient age and comorbidities. medRxiv, 2021.2003.2016.21253686 (2021).

47. R. Mitchell, D. F. Kelly, A. J. Pollard, J. Trück, Polysaccharide-specific B cell responses to vaccination in humans. Hum. Vaccin. Immunother. 10, 1661-1668 (2014). doi:10.4161/hv.28350 Medline

48. C. Dendle, R. L. Stuart, K. R. Polkinghorne, A. Balloch, J. Kanellis, J. Ling, M. Kummrow, C. Moore, K. Thursky, J. Buttery, K. Mulholland, P. Y. Gan, S. Holdsworth, W. R. Mulley, Seroresponses and safety of 13-valent pneumococcal conjugate vaccination in kidney transplant recipients. Transpl. Infect. Dis. 20 e12866 (2018). doi:10.1111/tid.12866 Medline

49. E. Schrezenmeier, L. Bergfeld, D. Hillus, J.-D. Lippert, U. Weber, P. Tober-Lau, I. Landgraf, T. Schwarz, K. Kappert, A.-L. Stefanski, A. Sattler, K. Kotsch, T. Doerner, L. E. Sander, K. Budde, F. Halleck, F. Kurth, V. M. Corman, M. Choi, Immunogenicity of COVID-19 Tozinameran Vaccination in Patients on Chronic Dialysis. medRxiv, 2021.2003.2031.21254683 (2021).

50. A. Sattler, E. Schrezenmeier, U. A. Weber, A. Potekhin, F. Bachmann, H. StraubHohenbleicher, K. Budde, E. Storz, V. Proß, Y. Bergmann, L. M. Thole, C. Tizian, 0. Hölsken, A. Diefenbach, H. Schrezenmeier, B. Jahrsdörfer, T. Zemojtel, K. Jechow, C. Conrad, S. Lukassen, D. Stauch, N. Lachmann, M. Choi, F. Halleck, K. Kotsch, Impaired humoral and cellular immunity after SARS-CoV2 BNT162b2 (Tozinameran) prime-boost vaccination in kidney transplant recipients. medRxiv 2021.2004.2006.21254963 (2021). Medline

51. M. Ferreira-Gomes, A. Kruglov, P. Durek, F. Heinrich, C. Tizian, G. A. Heinz, A. Pascual-Reguant, W. Du, R. Mothes, C. Fan, S. Frischbutter, K. Habenicht, L. Budzinski, J. Ninnemann, P. K. Jani, G. M. Guerra, K. Lehmann, M. Matz, L. Ostendorf, L. Heiberger, H. D. Chang, S. Bauherr, M. Maurer, G. Schönrich, M. Raftery, T. Kallinich, M. A. Mall, S. Angermair, S. Treskatsch, T. Dörner, V. M. Corman, A. Diefenbach, H. D. Volk, S. Elezkurtaj, T. H. Winkler, J. Dong, A. E. Hauser, H. Radbruch, M. Witkowski, F. Melchers, A. Radbruch, M. F. Mashreghi, SARS-CoV-2 in severe COVID-19 induces a TGF- $\beta$-dominated chronic immune response that does not target itself. Nat. Commun. 12, 1961 (2021). doi:10.1038/s41467-021-22210-3 Medline

Acknowledgments: The authors are grateful to Dr. Michael Moesenthin, Dr. Peter Bartsch (both Dialysezentrum Burg), Dr. Ralf Kühn, Dr. Dennis Heutling (both Dialyse Tangermünde), Dr. Petra Pfand-Neumann (Nierenzentrum Köthen) and Dr. Jörg-Detlev Lippert (MVZ Diaverum, Neubrandenburg) for patient recruitment as well as Dr. Petra Glander and Pia Hambach for biobanking of samples. Funding: ES was funded by the Federal Ministry of Education and
Research (BMBF) grant BCOVIT, 01KI20161. ES received a grant by the Berlin Institute of Health with the Charite Clinician Scientist Program funded by the Charite -Universitätsmedizin Berlin and the Berlin Institute of Health. MFM received a Starting Grant-Multi-Omics Characterization of SARS-CoV-2 infection, Project 6 "Identifying immunological targets in Covid-19" from the Berlin Institute of Health. HS is receives funding by the Ministry for Science, Research and Arts of Baden-Württemberg, Germany. ALS is funded by a scholarship of the German Society of Rheumatology. AS and KK receive funding by the Sonnenfeldstiftung Berlin, Germany. TD is grantholder oft the Deutsche Forschungsgemeinschaft grants KO 2270/7 1, KO-2270/4-1 (KK); Do491/7-5, 10-2, 11-1, Transregio 130 TP24. MFM receives funding of the State of Berlin and the "European Regional Development Fund" with the grant ERDF 2014-2020, EFRE 1.8/11. AR is funded though the Deutsche Forschungsgemeinschaft (DFG) through the TRR130-P16 and TRR241 B03 grants. MFM is part of the Leibniz Association (Leibniz Collaborative Excellence, TargArt). HRA holds a scholarship of the COLCIENCIAS scholarship No. 727, 2015. AS and KK receive funding by a grant of the Chiesi GmbH. Author contributions: HRA, ES, ACL, ALS and TD developed the concept of the study. KB, FH, MC, UW, AS and ES collected patient's samples. FSZ, ALS, HRA, HS, BJ, KL, GMG, MFG, MFM, AP, YC obtained the data. HR, ES, ALS, MFG, MFM and ACL, PD, FH analyzed the data. TD, ES, AS ALS and HR developed the theoretical framework. ACL, KK, KUE, GB, KB, AR and TD supervised the work. All authors developed, read, and approved the current manuscript. Competing interests: Authors declare that they have no competing interests. Data and materials availability: All data are available in the main text or the supplementary materials. Data from transcriptome sequencing and immune profiling in GEO under the accession GSE176442. This work is licensed under a Creative Commons Attribution 4.0 International (CC BY 4.0) license, which permits unrestricted use, distribution, and reproduction in any medium, provided the original work is properly cited. To view a copy of this license, visit https://creativecommons.org/licenses/by/4.0/. This license does not apply to figures/photos/artwork or other content included in the article that is credited to a third party; obtain authorization from the rights holder before using such material.

Submitted 20 April 2021

Accepted 9 June 2021

Published First Release 15 June 2021

10.1126/sciimmunol.abj1031 
A

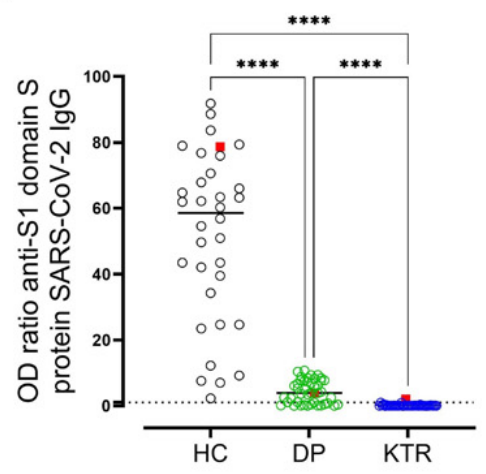

D

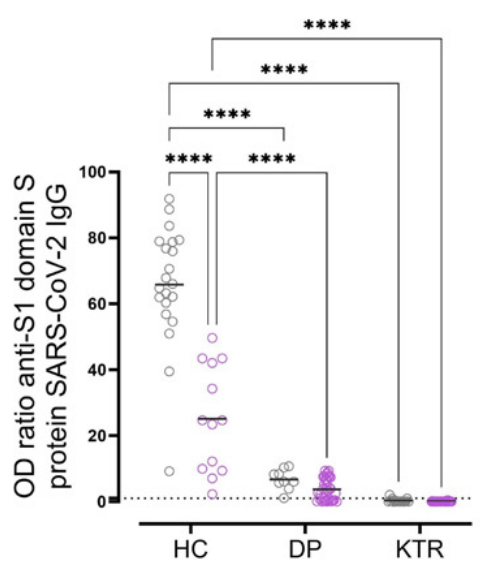

G

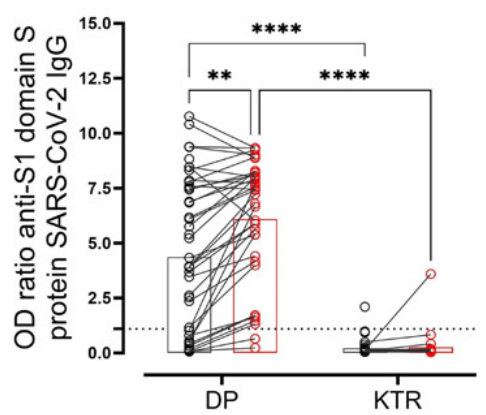

B

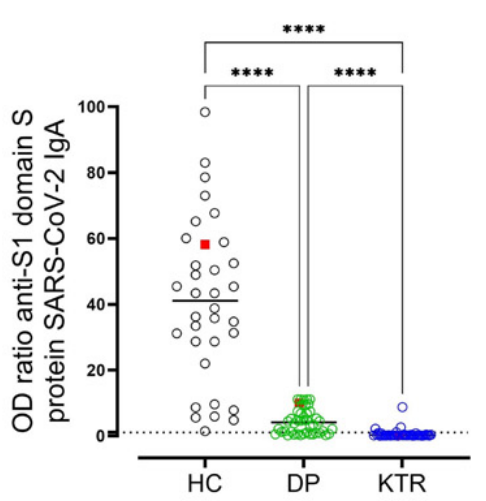

E

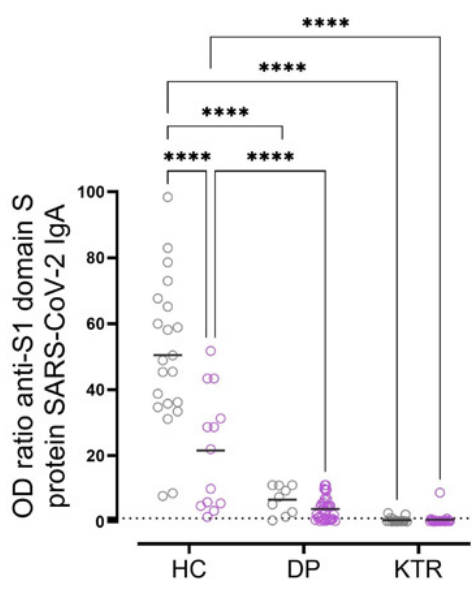

H

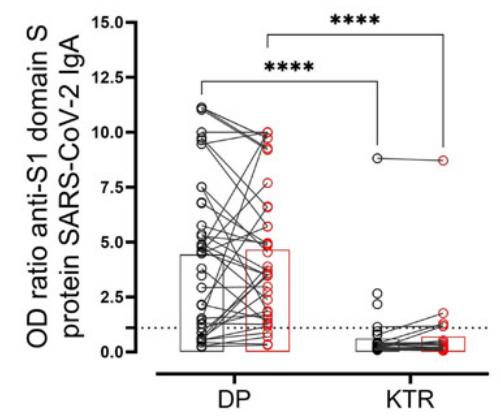

C

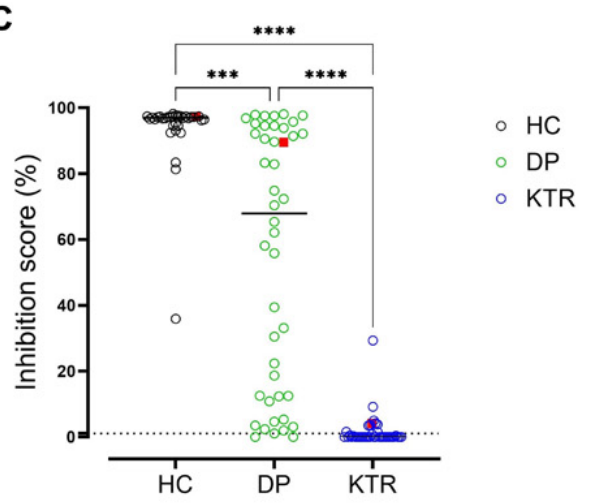

F

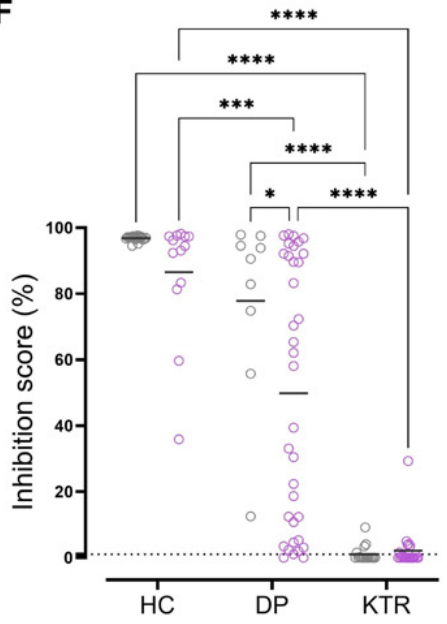

I

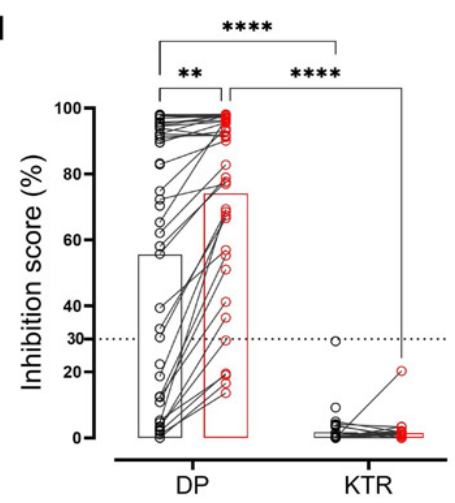

- Age $<60$

- Age $>60$
-1 week after Boost

$\rightarrow 3$ weeks after Boost

Fig. 1. Humoral immune response was delayed in DP and markedly reduced in KTR. (A-C) Humoral immune response against SARS-CoV-2 was assessed by Euroimmune ELISA for (A) spike protein S1 IgG, (B) spike protein S1 IgA and $(C)$ virus neutralization by a blocking ELISA in HC $(n=34)$, DP $(n=44)$ and KTR $(n=40) 7 \pm 2$ days after $2 n d$ vaccination with BNT162b2 in the total cohort. (D-F) Humoral immune response with each cohort divided according to age ( $>60 n=71(\mathrm{HC} n=13$, DP $n=35, K T R n=23)$ and $<60$ years $n=47(\mathrm{HC} \mathrm{n=21,DP} n=9, K T R n=17)$ ) into two subgroups and the corresponding results are shown for (D) spike protein S1 IgG, (E) spike protein S1 IgA and (F) virus neutralization by a blocking ELISA. (G-I) Follow-up sera were collected from 37 DP and 26 KTR patients, respectively 3-4 weeks after 2 nd vaccination and investigated for (G) spike protein S1 IgG, (H) spike protein S1 IgA $a$ and $(I)$ virus neutralization by a blocking ELISA. (A-I) Threshold of upper limit of normal is indicated as dotted lines. (A-F) Kruskal-Wallis with Dunn's post-test. Previously infected individuals are indicated in red. (G-I) Two-way ANOVA with Šidák's post-test. ${ }^{*} p<0.05,{ }^{* *} p<0.01,{ }^{* *} p<0.001,{ }^{* * *} p<0.0001$. 
A

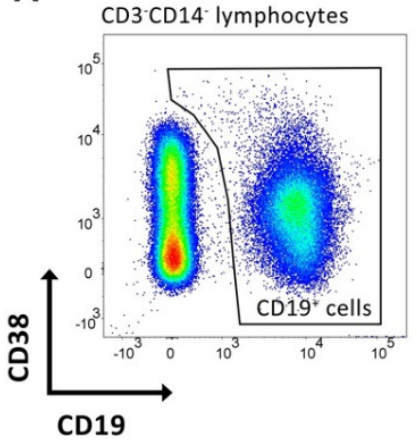

B

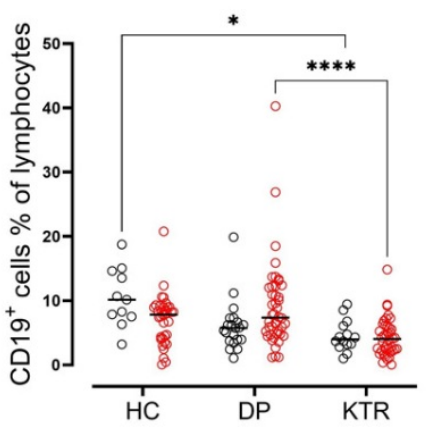

D

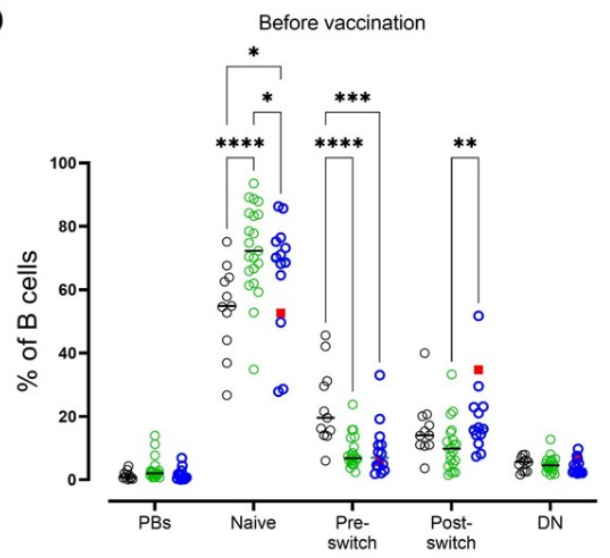

F

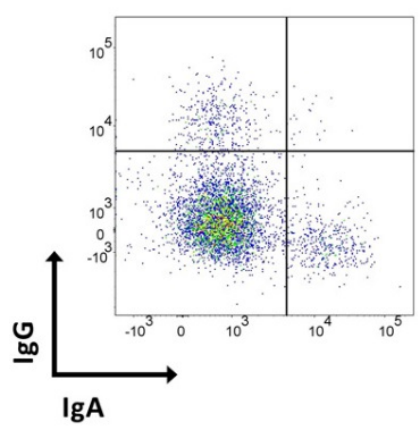

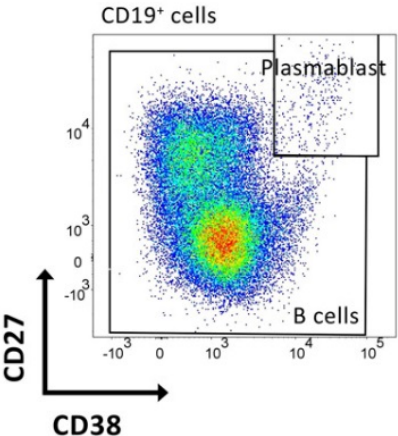

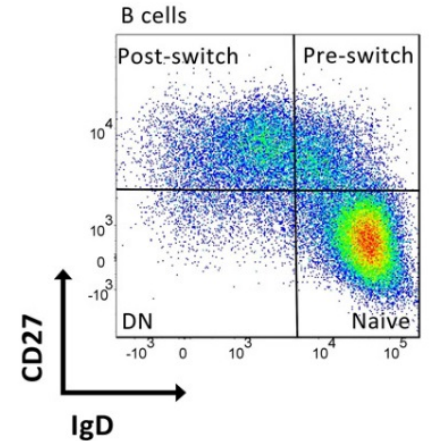

C

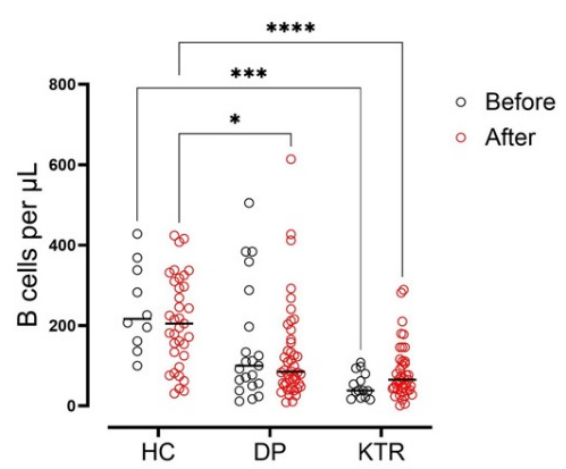

E

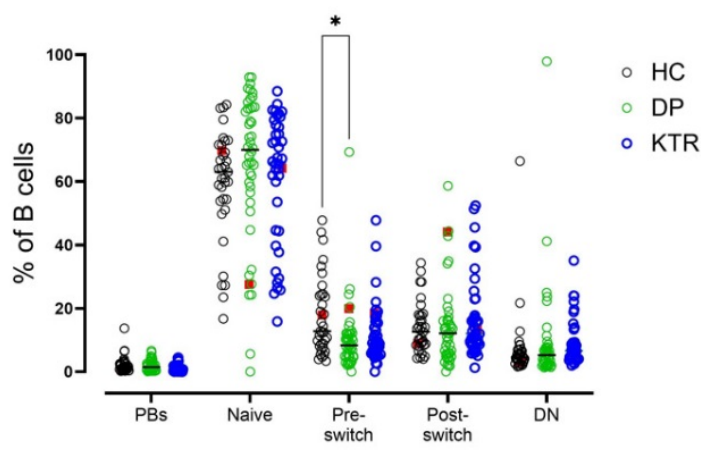

G

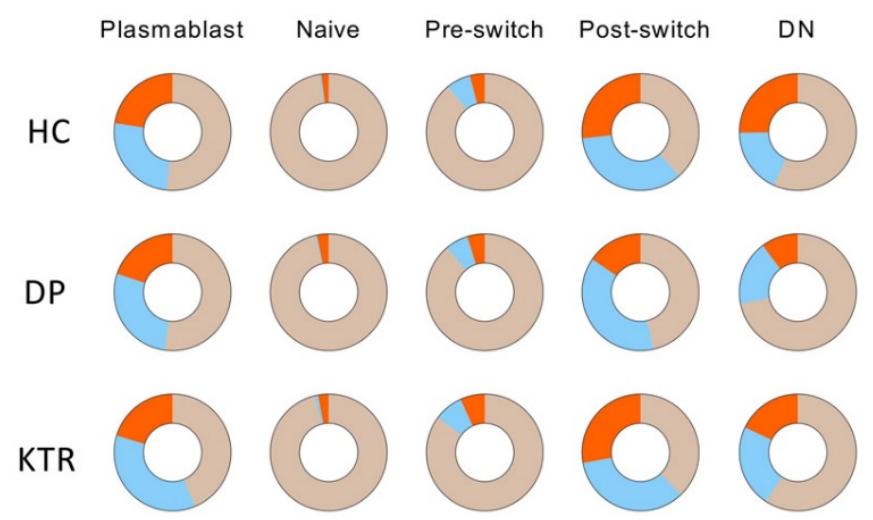

Fig. 2. B cells were reduced in DP and KTR but show a similar distribution after 2nd BNT162b2 vaccination. (A) Representative pseudocolor plots of CD19+ B cell gating into plasmablasts and mature B cells, and representative

pseudocolor plots of IgD/CD27 based classification.

Frequency of CD19+ B cells (gates shown in (A)) in HC, DP and KTR before vaccination ( $n=46:$ HD $n=11, \quad D P$ $\mathrm{n}=21$ and $\mathrm{KTR} \mathrm{n}=14$ ) and $7 \pm 2$ days after 2nd vaccination ( $n=119$ : HD $\mathrm{n}=35$, DP $\mathrm{n}=44$ and $\mathrm{KTR}$ $\mathrm{n}=40$ ) with BNT162b2. (C) Corresponding absolute numbers (per $\mu$ l blood) measured by BD Trucount

Frequencies of plasmablasts and mature B cells according to $\mathrm{CD} 27 / \operatorname{lgD}$ (gates shown in $(A)$ ) at (D) baseline $(n=46: \mathrm{HD}$ $\mathrm{n}=11, \mathrm{DP} \mathrm{n}=21$ and $\mathrm{KTR}$ $\mathrm{n}=14$ ) and (E) $7 \pm 2$ days after 2nd vaccination $(n=119: \quad H D n=35, \quad D P$ $n=44$ and KTR $n=40$ ). (F) Representative pseudocolor plot of IgA and IgG expression in $B$ cells from HC. (G) Distribution of surface immunoglobulin isotype expression among $\mathrm{HC}$, $\mathrm{DP}$ and KTR $7 \pm 2$ days after 2nd vaccination $(n=119: H D n=35, D P$ $n=44$ and $K T R \quad n=40$ ). Two-way ANOVA with Šidák's post-test. ${ }^{*} \mathrm{p}<0.05, \quad{ }^{* *} \mathrm{p}<0.01$, $* * * p<0.001$, $* * * * p<0.0001$.

immunology.sciencemag.org 
A

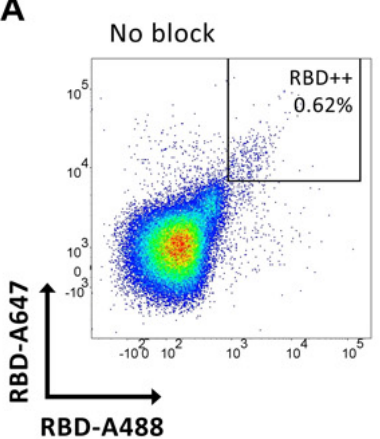

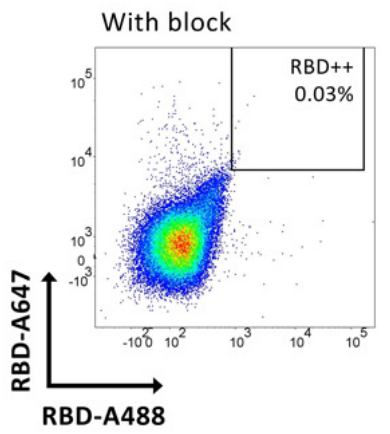

B

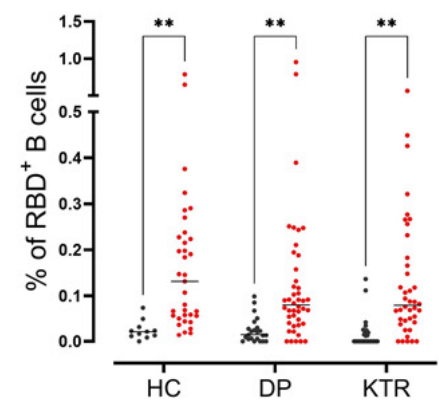

C

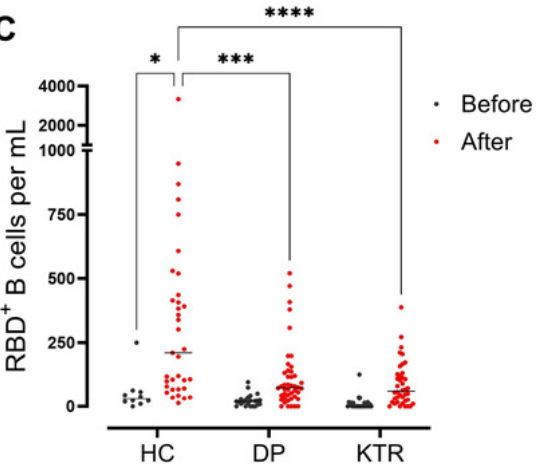

D

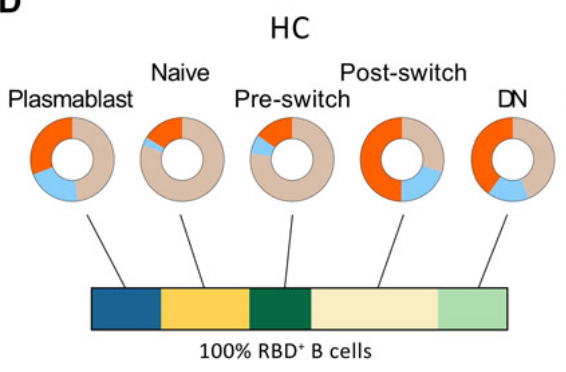

DP

KTR
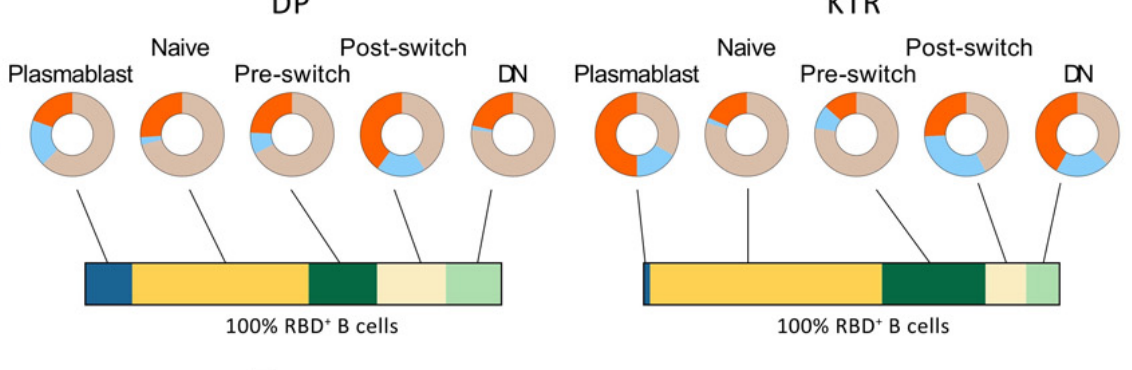

$=\lg G$

$=\lg A$

$=\lg A \cdot \lg G$

E

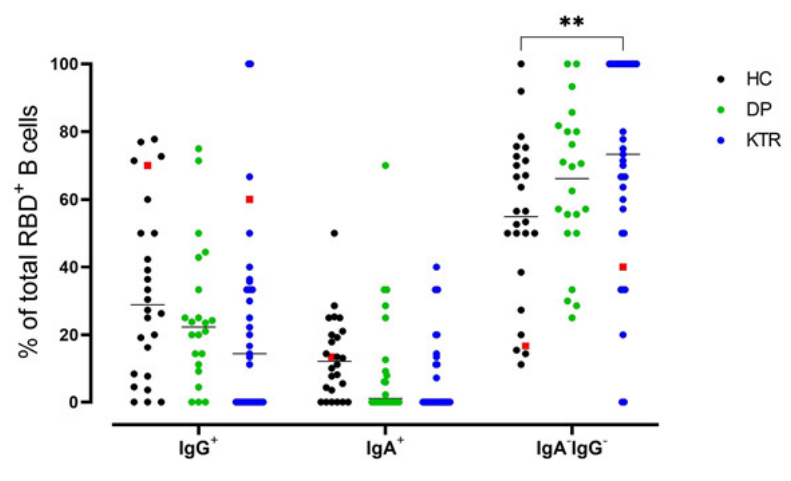

F

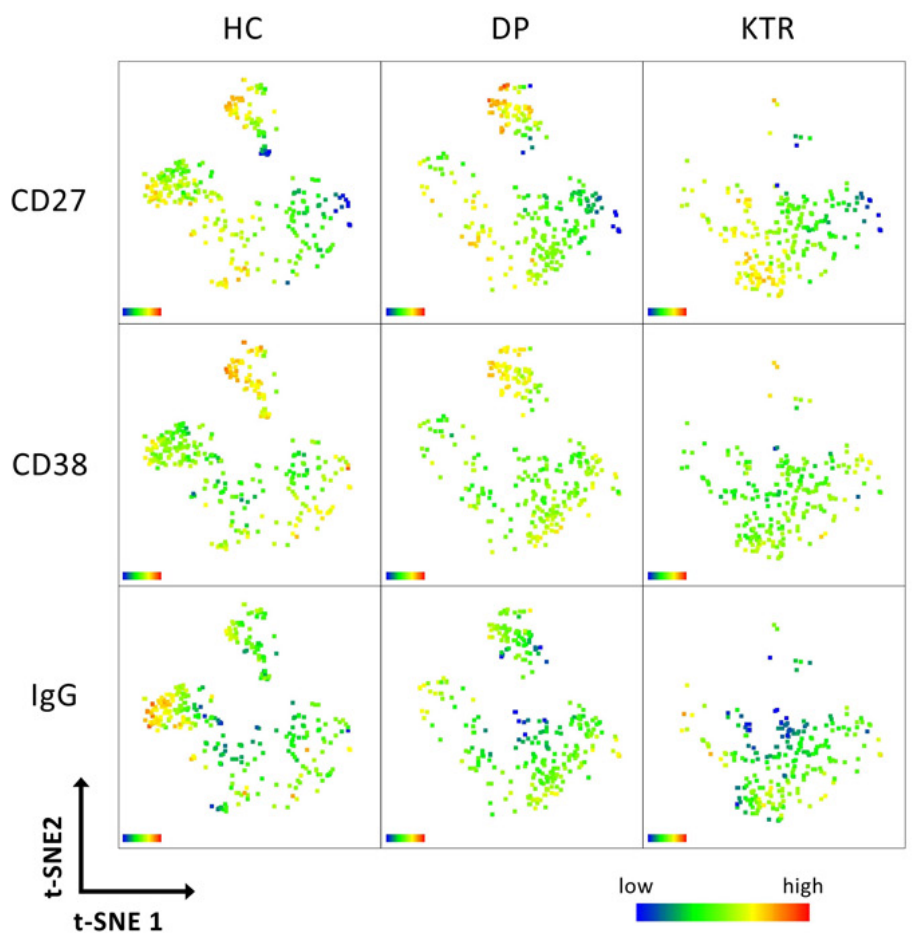

Fig. 3. RBD-specific $B$ cells were present in DP and KTR patients after BNT162b2 vaccination but populate different $B$ cell subsets. (A) Representative dot plot of double positive cells RBD-specific B cells before and after blocking with unlabeled RBD are shown. (B) Frequencies and $(C)$ absolute numbers of RBD+ cells among total $C D 19+B$ cells measured before $(n=59$ : $H D$ $n=10, D P n=23$ and $K T R n=26)$ and $7 \pm 2$ days after 2 nd vaccination $(n=119: H D n=35, D P n=44$ and $K T R \quad n=40)$. (D) Frequencies of plasmablasts, naïve, pre-switch, post-switch and double negative B cells (bar) and immunoglobulin isotype distribution among subsets (cakes) ( $H D n=10, D P n=23$ and $K T R n=26)$. (E) Immunoglobulin isotype expression among total $\mathrm{RBD}+$ cells in HC, DP and KTR and $7 \pm 2$ days after 2 nd vaccination ( $H D n=35, D P n=44$ and $K T R n=40)$. (F) Two-dimensional $\mathrm{t}-\mathrm{SNE}$ of all RBD+ cells in HC ( $n=21)$, DP $(n=23)$ and KTR $(n=34)$. Color code indicates expression of CD27 (upper panel), CD38 (middle panel) and lgG (lower panel). Previously infected individuals are marked red (E). (B-D) Two-way ANOVA with Sidák's post-test. (E) Kruskal-Wallis with Dunn's post-test. ${ }^{*} p<0.05,{ }^{* *} p<0.01,{ }^{* *} p<0.001,{ }^{* * *} p<0.0001$. 
A

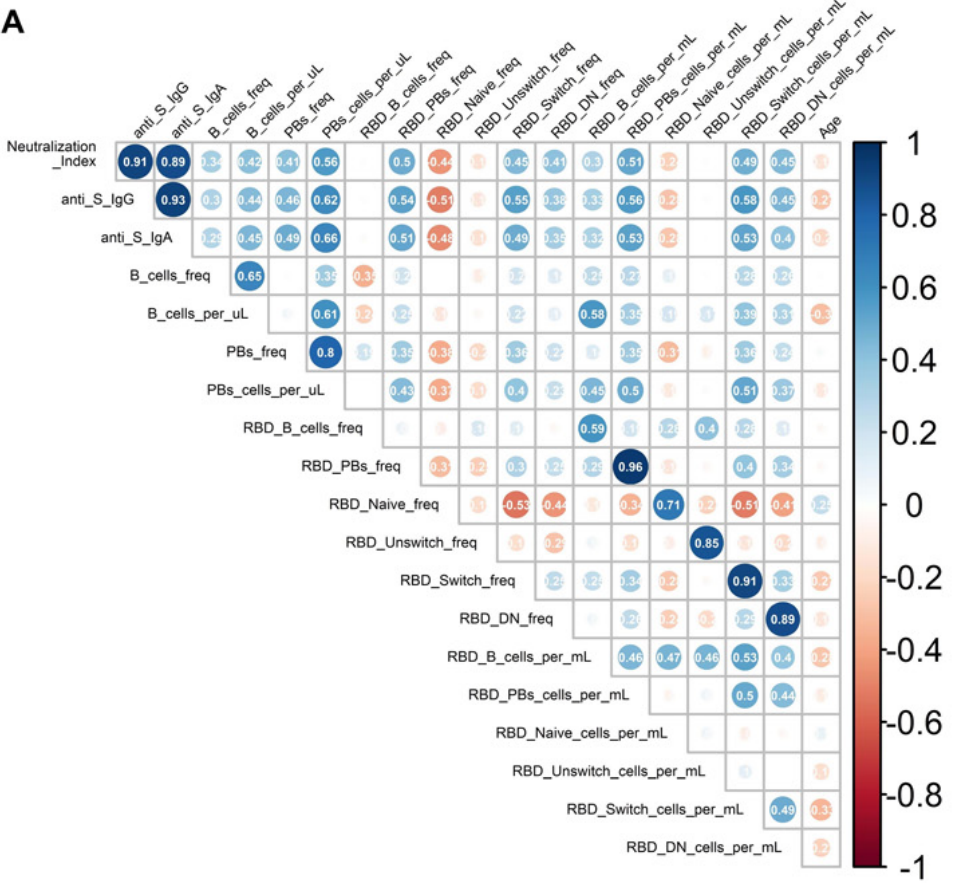

B
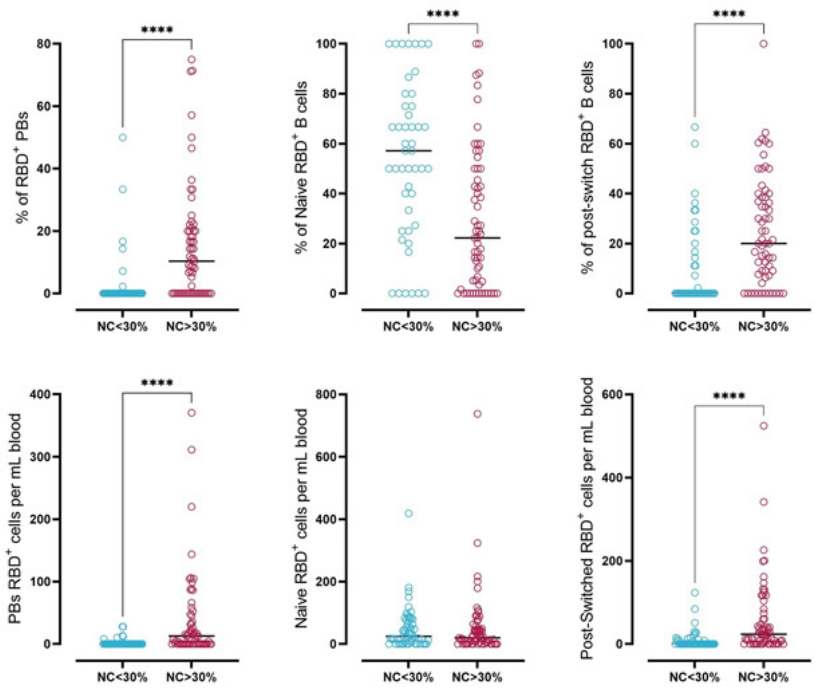

Fig. 4. Correlation of anti-BNT162b2 serological and B cell responses. (A) Spearman's correlation matrix showing the correlation of frequency of RBD+ cells in each $B$ cell subset in the cohort. Corresponding correlations are represented by red (negative) or blue (positive) circles; size and intensity of color refer to the strength of correlation ( $H D n=35$, DP $n=44$ and KTR $n=40$ ). Only correlations with $p \leq 0.05$ are indicated. (B) Frequency (upper panel) and absolute numbers (lower panel) of RBD+ plasmablasts (PB), naïve $B$ cells and post-switch $B$ cells in non-responders (surrogate virus neutralization capacity $((\mathrm{NC}) \mathrm{NC}<30 \%, \mathrm{n}=55)$ and responders $(\mathrm{NC}>30 \%, \mathrm{n}=63)$. Each point represents a donor. Unpaired two-sided Mann-Whitney $U$ test. ${ }^{*} p<0.05,{ }^{* *} p<0.01,{ }^{* * *} p<0.001$, **** $p<0.0001$. 
Table 1. Patient characteristics.

$\begin{array}{cccc}\text { HC } & \text { KTR } & \text { HD } & \text { PD } \\ \mathrm{N}=35 & \mathrm{~N}=40 & \mathrm{~N}=40 & \mathrm{~N}=4\end{array}$

Age

Median [IQR]

Under 50

Between 51-59

Between 60-69

$>70$

Sex

Male

Female

Renal replacement therapy

Years since renal replacement therapy

Median [IQR]

Years since kidney transplantation

Median [IQR]

Immunosuppression

Steroid+Tacrolimus+MMF (\%)

Steroid+CyA+Azathioprine (\%)

Steroid+CyA+MMF (\%)

mTORi+MMF \pm Steroid (\%) 3 (7.69)

mTORi+CyA+MMF (\%) 1 (2.56)

MMF (total)

$2 \mathrm{~g}$

$>1 \mathrm{~g}$ and $<2 \mathrm{~g}$

$\leq 1 \mathrm{~g}$

Cadaveric kidney donor

Living kidney donor

Retransplantation

\section{Co-Morbidities}

Hypertension

Diabetes mellitus

Malignancy, recent or history of

$\begin{array}{cccr}51.0 & 62.4 & 69.0 & 70.5 \\ {[34.0,80]} & {[51.25,69.5]} & {[81.575,} & {[80.5,63} \\ 17 & & 63.0] & \\ 5 & 7 & 3 & 0 \\ 4 & 10 & 6 & 0 \\ 9 & 15 & 13 & 2 \\ & 8 & 18 & 2\end{array}$

20

28

25

3

15

12

15

1
5.5

$[2.0,9.0]$

5.0

$[2.0,10.0]$

22

1

13

3

1

39

12

11

16

34

6

6

0.5

63.5]

0 